\title{
Anomalous Temperature Dependence of Hydrogen Permeability through Palladium-Silver Binary Alloy Membrane and Its Analysis Based on Hydrogen Chemical Potential
}

\author{
A. Suzuki ${ }^{1, * 1}$, H. Yukawa ${ }^{1, * 2}$, T. Nambu ${ }^{2}$, Y. Matsumoto ${ }^{3}$ and Y. Murata ${ }^{1}$ \\ ${ }^{1}$ Department of Materials Science and Engineering, Graduate School of Engineering, Nagoya University, Nagoya 464-8603, Japan \\ ${ }^{2}$ National Institute of Technology, Suzuka College, Suzuka 510-0294, Japan \\ ${ }^{3}$ National Institute of Technology, Oita College, Oita 870-0152, Japan
}

\begin{abstract}
The hydrogen permeability of Pd-Ag alloy membranes has been investigated over a wide temperature range between $100^{\circ} \mathrm{C}$ and $500^{\circ} \mathrm{C}$. The hydrogen permeation coefficient, $\Phi$, for $\mathrm{Pd}-23 \mathrm{~mol} \% \mathrm{Ag}$ decreases with decreasing temperature above $300^{\circ} \mathrm{C}$, in good agreement with the previous literature. However, $\Phi$ starts to increases below $250^{\circ} \mathrm{C}$, and a peak is observed at around $180^{\circ} \mathrm{C}$. Considering the silver concentration and operating temperature, the $\alpha-\alpha^{\prime}$ phase transition never occurs in this condition. In other words, the $\alpha-\alpha^{\prime}$ phase transition is not the reason for the anomalous peak behavior of $\mathrm{Pd}-23 \mathrm{~mol} \% \mathrm{Ag}$ alloy at low temperature. In addition, it is confirmed that the diffusion-limiting hydrogen permeation reaction takes place from room temperature up to $500^{\circ} \mathrm{C}$. To understand the reason for the peak appearance, the hydrogen permeability has been analyzed in view of the new description of hydrogen permeation based on hydrogen chemical potential. As a result, it is found that the temperature dependence of the PCT factor, $f_{\mathrm{PCT}}$, is dominant for the peak appearance, meaning that the corresponding pressure-composition-isotherms (PCT curves) are essential for the understanding of hydrogen permeability of the alloy. Dependences of the pressure condition and silver concentration on the peak behavior have also been investigated. The peak temperature increases with increasing the hydrogen pressure at feed side. In addition, the peak appears at lower temperature and becomes remarkable with decreasing silver concentration of Pd-Ag alloy membrane. In other words, the composition of Pd-Ag alloy membranes must be designed based on the operating temperature or pressure condition. Thus, this study suggests new possibilities of alloy design for Pd-Ag alloy membranes. [doi:10.2320/matertrans.M2016020]
\end{abstract}

(Received January 19, 2016; Accepted February 19, 2016; Published April 8, 2016)

Keywords: hydrogen permeable membrane, Pd-based alloys, $\alpha-\alpha$ ' phase transition, rate-limiting process, hydrogen chemical potential

\section{Introduction}

The hydrogen permeable metal membranes are important key materials for hydrogen separation and purification technologies ${ }^{1-5)}$. For example, palladium has high hydrogen permeability with strong resistance to the hydrogen embrittlement, and $\mathrm{Pd}$-based alloys are widely used practically to obtain high purity hydrogen from a mixture gas containing hydrogen ${ }^{5}$.

Among the Pd-based alloys, $\mathrm{Pd}-\mathrm{Ag}$ binary alloys have been widely investigated. It is reported that the addition of silver into palladium enhances the hydrogen permeability and it reaches the maximum when the silver concentration is about $23 \mathrm{~mol}^{6,7)}$. In addition, the material cost of silver is lower than that of palladium. Thus, the addition of silver reduces the cost. The addition of silver into palladium also enhances the durability of the membrane by suppressing the $\alpha-\alpha^{\prime}$ phase transition below $298^{\circ} \mathrm{C}^{8-16)}$. Therefore, $\mathrm{Pd}-\mathrm{Ag}$ alloys are one of the most promising materials for hydrogen permeable metal membranes.

On the other hand, it is generally considered that the hydrogen permeability for $\mathrm{Pd}$-based alloy membranes declines with decreasing temperature, and unable to use at low temperature below $300^{\circ} \mathrm{C}$. Therefore, the hydrogen permeability for $\mathrm{Pd}-\mathrm{Ag}$ binary alloys at low temperature below $300^{\circ} \mathrm{C}$ seems to have not been understood correctly.

In this study, the hydrogen permeability for $\mathrm{Pd}-\mathrm{Ag}$ binary alloys has been investigated over a wide temperature range. In addition, the temperature dependence of the hydrogen per-

\footnotetext{
${ }^{*}$ Graduate Student, Nagoya University

${ }^{* 2}$ Corresponding author, E-mail: hiroshi@nagoya-u.jp
}

meability is discussed in detail in view of the hydrogen diffusivity and solubility.

\section{Experimental Procedure}

\subsection{Hydrogen permeation tests}

$\mathrm{Pd}-20 \mathrm{~mol} \% \mathrm{Ag}, \mathrm{Pd}-23 \mathrm{~mol} \% \mathrm{Ag}$ and $\mathrm{Pd}-27 \mathrm{~mol} \% \mathrm{Ag}$ foils are prepared. The thickness of each sample is $25 \mu \mathrm{m}$ for Pd$20 \mathrm{~mol} \% \mathrm{Ag}, 30 \mu \mathrm{m}$ and $60 \mu \mathrm{m}$ for $\mathrm{Pd}-23 \mathrm{~mol} \% \mathrm{Ag}$ and $50 \mu \mathrm{m}$ for Pd-27mol\% Ag. They are cut into disks with $\phi 12 \mathrm{~mm}$ in diameter and are annealed in vacuum at $700^{\circ} \mathrm{C}$ for $3.6 \mathrm{ks}$.

The hydrogen permeation tests are performed at $22^{\circ} \mathrm{C} \sim 500^{\circ} \mathrm{C}$ by the conventional gas permeation method with differential pressure ${ }^{17)}$. The disk sample is set into a cell for the hydrogen permeation test apparatus and then evacuated. Subsequently, so-called "air-treatment" is performed ${ }^{18)}$. First, the sample cell is heated up to $500^{\circ} \mathrm{C}$. Then ambient pressure of air is introduced into the system and wait for $600 \mathrm{~s}$. The sample cell is evacuated again and then high purity (99.99999\%) hydrogen gas is introduced into the system. A series of this oxidation and reduction process activates the sample surface for the hydrogen permeation. The testing conditions of the temperature as well as the hydrogen pressures at the feed and permeation sides of the membrane are listed in Table 1 . The hydrogen flux which permeates the disk sample is measured by monitoring the pressure change of the reserve tank with known volume. The detailed explanation of the hydrogen permeation test is given elsewhere ${ }^{17}$.

\subsection{Pressure-composition-isotherm measurements}

The pressure-composition-isotherms (PCT curves) are measured for $\mathrm{Pd}-23 \mathrm{~mol} \% \mathrm{Ag}$ alloys by using a Sieverts-type 
Table 1 Pressure and temperature conditions of hydrogen permeation tests.

\begin{tabular}{|c|c|c|c|}
\hline \multirow{2}{*}{ Sample } & \multicolumn{2}{|c|}{ Hydrogen pressure, $P / \mathrm{MPa}$} & \multirow{2}{*}{ Temperature, $T /{ }^{\circ} \mathrm{C}$} \\
\hline & Feed & Permeation & \\
\hline $\mathrm{Pd}-20 \mathrm{~mol} \% \mathrm{Ag}$ & 0.10 & 0.01 & $100 \sim 500$ \\
\hline \multirow{8}{*}{$\mathrm{Pd}-23 \mathrm{~mol} \% \mathrm{Ag}$} & 0.10 & 0.01 & $22 \sim 500$ \\
\hline & 0.25 & 0.10 & \multirow{7}{*}{$100 \sim 500$} \\
\hline & 0.50 & 0.10 & \\
\hline & 0.80 & 0.10 & \\
\hline & 1.00 & 0.10 & \\
\hline & 1.00 & 0.20 & \\
\hline & 1.00 & 0.40 & \\
\hline & 1.00 & 0.80 & \\
\hline $\mathrm{Pd}-27 \mathrm{~mol} \% \mathrm{Ag}$ & 0.10 & 0.01 & $100 \sim 500$ \\
\hline
\end{tabular}

apparatus in order to investigate the hydrogen solubility. A small piece of the sample is set into a cell for the PCT apparatus and then evacuated. Subsequently, it is heated up to about $500^{\circ} \mathrm{C}$, and about $5 \mathrm{MPa}$ of high purity hydrogen is introduced and then the sample cell is cooled down to room temperature. This activation process is repeated 4 times prior to the PCT measurements. The PCT curves are measured at $100^{\circ} \mathrm{C} \sim 400^{\circ} \mathrm{C}$ up to about $2 \mathrm{MPa}$.

\section{Results and Discussion}

\subsection{Temperature dependence of hydrogen permeability}

To understand the temperature dependence of the hydrogen permeability, the apparent hydrogen permeation coefficient, $\Phi$, is determined by the following equation.

$$
\Phi=\frac{J \cdot L}{\sqrt{P_{1}}-\sqrt{P_{2}}}
$$

where $J$ is the hydrogen flux, $L$ is the thickness of the membrane, $P_{1}$ and $P_{2}$ are the hydrogen pressures at the feed and permeation sides of the membrane.

Figure 1 shows the Arrhenius plot of the hydrogen permeation coefficient, $\Phi$, for $\mathrm{Pd}-23 \mathrm{~mol} \% \mathrm{Ag}$ alloy membrane with the thickness of $30 \mu \mathrm{m}$. The hydrogen pressures at the feed and permeation sides of the membrane, $P_{1}$ and $P_{2}$, are fixed to be $0.10 \mathrm{MPa}$ and $0.01 \mathrm{MPa}$, respectively. As shown in Fig. 1, the value of $\Phi$ decreases linearly with decreasing temperature above $300^{\circ} \mathrm{C}$, in good agreement with the previous report ${ }^{19}$ ) which is shown in Fig. 1 by a dotted line. However, it is very interesting that, below $250^{\circ} \mathrm{C}$, the $\Phi$ value starts to increase with decreasing temperature and a peak is observed at around $180^{\circ} \mathrm{C}$. The value of $\Phi$ at $180^{\circ} \mathrm{C}$ is almost the same as that at $400^{\circ} \mathrm{C}$, meaning that the operating temperature can be greatly lowered for about $220^{\circ} \mathrm{C}$ without spoiling the hydrogen permeability. Utilizing this anomalous behavior of hydrogen permeability, the thermal efficiency of the production of high purity hydrogen will be improved by operating the membrane at low temperature as low as $180^{\circ} \mathrm{C}$. It is also possible to reduce greatly the demand for heat resistance of the materials of the surrounding components. Thus, this anomalous temperature dependence of hydrogen permeability has great possibility of new application of the Pd-based alloy membrane.

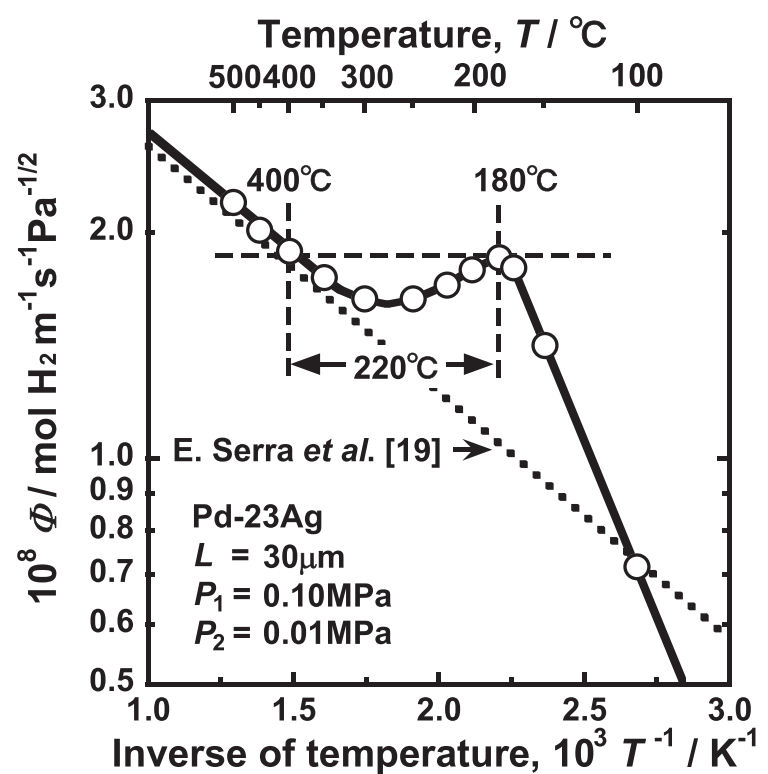

Fig. 1 Arrhenius plot of hydrogen permeation coefficient for $\mathrm{Pd}-$ $23 \mathrm{~mol} \% \mathrm{Ag}$ alloy membrane.

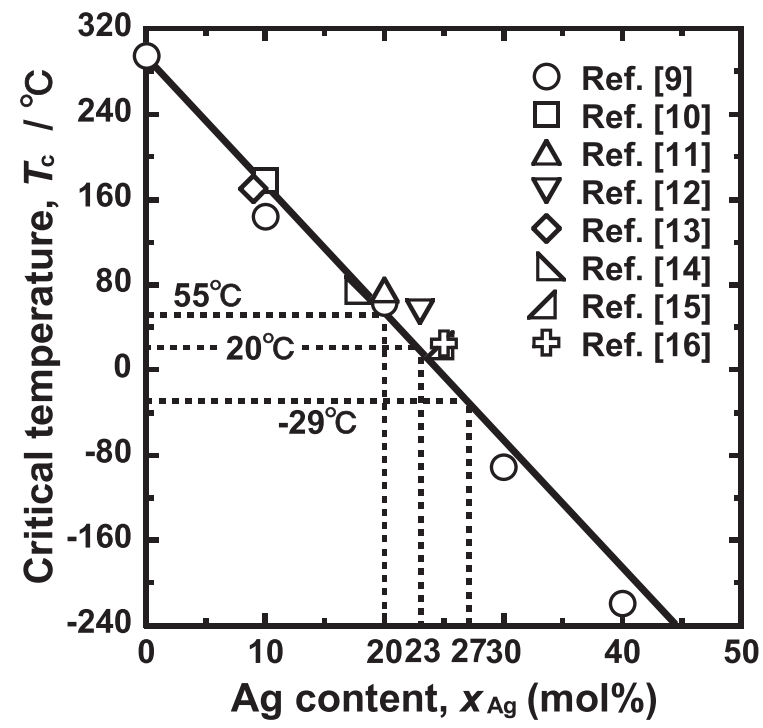

Fig. 2 Correlation between the critical temperature for the miscibility gap of the $\alpha-\alpha^{\prime}$ transformation and mole fraction of $\mathrm{Ag}$ content in $\mathrm{Pd}-\mathrm{Ag}-\mathrm{H}$ ternary system ${ }^{9-16)}$

\section{2 $\alpha-\alpha^{\prime}$ phase transition}

Similar temperature dependence of the hydrogen permeability has been reported previously ${ }^{20}$, but the reason of the anomalous behavior is understood by the $\alpha-\alpha^{\prime}$ phase transition $^{20)}$. In such case, operating the membrane at the peak temperature declines the durability due to reported $\alpha-\alpha^{\prime}$ phase transition. On the other hand, as mentioned above, the addition of silver into palladium suppresses the $\alpha-\alpha^{\prime}$ phase transition. In this study, the critical temperature, $T_{\mathrm{c}}$ of the $\alpha-\alpha^{\prime}$ miscibility gap for $(\mathrm{Pd}-\mathrm{Ag})-\mathrm{H}$ pseudobinary systems in the literatures is researched ${ }^{9-16)}$, and the correlation between $T_{\mathrm{c}}$ and the silver concentration is shown in Fig. 2. As shown in Fig. 2, it is interesting that $T_{\mathrm{c}}$ decreases almost linearly with increasing silver concentration in $\mathrm{Pd}-\mathrm{Ag}$ system. For (Pd$23 \mathrm{~mol} \% \mathrm{Ag}$ ) $-\mathrm{H}$ pseudobinary system, $T_{\mathrm{c}}$ is estimated to be 

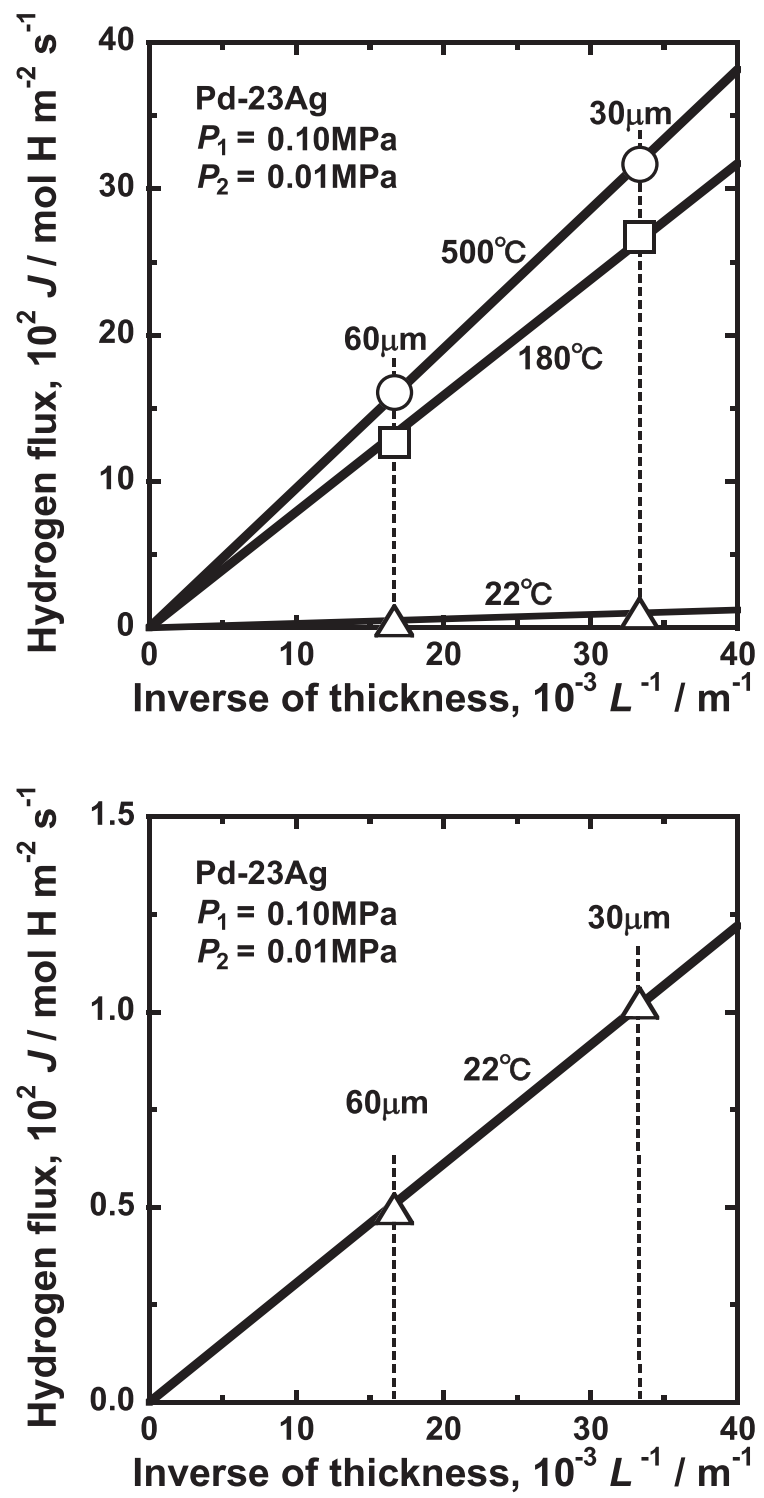

Fig. 3 Correlation between the hydrogen flux, $J$, and the inverse of thickness, $L^{-1}$, for Pd-23mol\%Ag alloy membrane.

about $20^{\circ} \mathrm{C}$. In other words, it is thought that the $\alpha-\alpha$ ' transition does not occur at the temperature range shown in Fig. 1. Here, it is important to note that the anomalous behavior of hydrogen permeability observed in Fig. 1 is not caused by the $\alpha-\alpha^{\prime}$ phase transition. Therefore, the peak behavior is applicable without declining the durability of the membrane.

\subsection{Rate-limiting process}

As shown in Fig. 1, the slope of the line below $180^{\circ} \mathrm{C}$ is steeper than that above $300^{\circ} \mathrm{C}$. In the previous study, it is also discussed in this point ${ }^{20)}$. It is suggested that the change in the slope observed at low temperature occurs due to the change in the rate-limiting process from the bulk diffusion control to the surface reaction control ${ }^{20)}$. Therefore, in this study, the ratelimiting process is investigated over a wide temperature range.

Figure 3 shows the correlation between the hydrogen flux, $J$, and the inverse of thickness, $L^{-1}$, for $\mathrm{Pd}-23 \mathrm{~mol} \% \mathrm{Ag}$ at $22^{\circ} \mathrm{C}, 180^{\circ} \mathrm{C}$ and $500^{\circ} \mathrm{C}$. It is evident that there is a linear relationship between $J$ and $L^{-1}$ at each temperature. The line

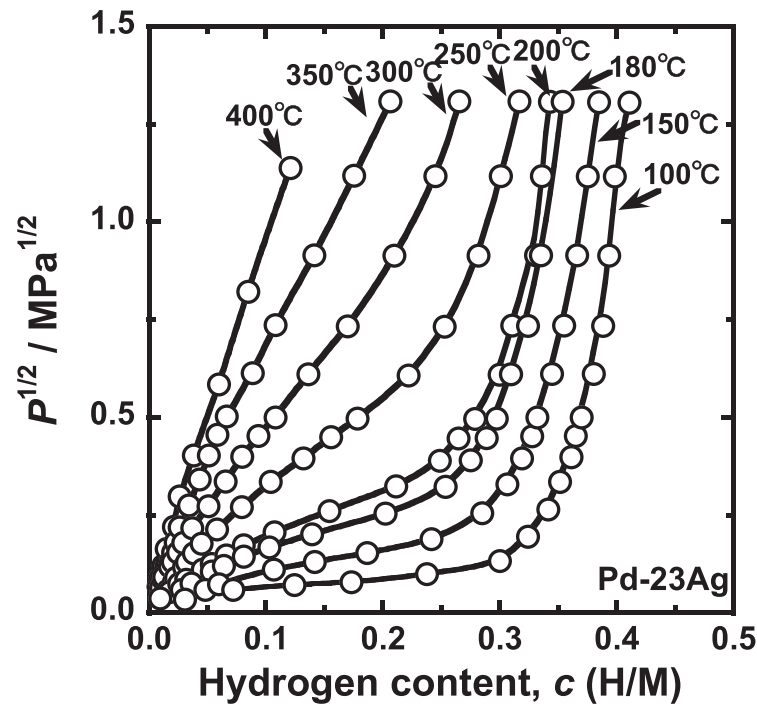

Fig. 4 Pressure-composition-isotherms (PCT curves) for Pd-23mol\% Ag alloy.

shown in Fig. 3 crosses at the origin, indicating that the diffusion-limiting hydrogen permeation reaction takes place at wide temperature range even at room temperature. Therefore, it is necessary to understand the dominant factor of the peak appearance in Fig. 1 in view of the diffusion of hydrogen atoms through metal membrane.

\subsection{Analysis of hydrogen permeability in view of Fick's diffusion equation}

For the diffusion-limiting hydrogen permeation reaction, the following Fick's diffusion equation is commonly applied to metal membranes to discuss the hydrogen permeation property of them.

$$
J=-D \frac{d c}{d x}
$$

where $D$ is the diffusion coefficient and $d c / d x$ is the gradient of hydrogen concentration. Applied to a membrane with a thickness of $L$, eq. (2) is modified as follows.

$$
J=D \frac{\Delta c}{L},
$$

where $\Delta c$ is the difference of hydrogen concentration between the feed and permeation sides of the membrane. Here, it is necessary to determine $\Delta c$ value at each temperature and pressure condition. In this study, it is estimated from the PCT curves for Pd-23mol\%Ag alloy shown in Fig. 4.

The steady-state hydrogen flux, $J$ is measured. It is divided by the inverse of the membrane thickness, $L^{-1}$, in order to estimate the normalized hydrogen flux, $J \cdot L$. It is noted here that the atomic hydrogen flux, mol $\mathrm{H} \mathrm{m}^{-1} \mathrm{~s}^{-1}$, is evaluated in this study, which is twice as large as the gaseous hydrogen flux, mol $\mathrm{H}_{2} \mathrm{~m}^{-1} \mathrm{~s}^{-1}$.

Figure 5 shows the correlation between the normalized hydrogen flux, $J \cdot L$, and the difference of hydrogen concentration, $\Delta c$, at the feed and permeation sides of the membrane. At $400^{\circ} \mathrm{C}$, there is a linear relationship between $J \cdot L$ and $\Delta c$. In contrast, at $200^{\circ} \mathrm{C}$, it is evident that datum are scattered and there is no liner relationship between $J \cdot L$ and $\Delta c$. Thus, the 


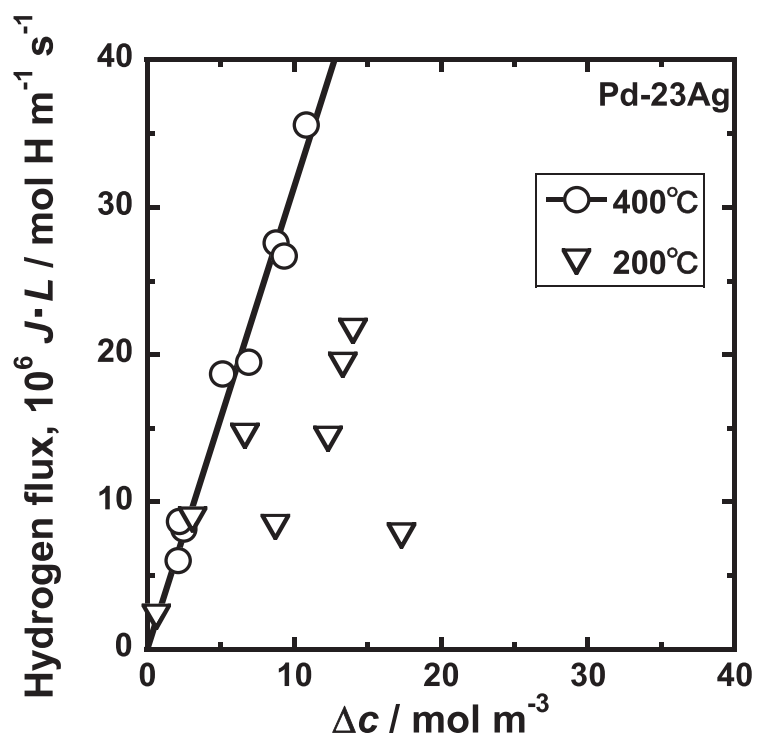

Fig. 5 Correlation between the normalized hydrogen flux, $J \cdot L$ and the difference of the hydrogen concentration at feed and permeation sides of the membrane, $\Delta c$, for $\mathrm{Pd}-23$ moll $\% \mathrm{Ag}$ alloy membrane measured at $200^{\circ} \mathrm{C}$ and $400^{\circ} \mathrm{C}$

hydrogen permeation property for $\mathrm{Pd}-23 \mathrm{~mol} \% \mathrm{Ag}$ especially at low temperature cannot be understood correctly by the analysis based on the Fick's law.

\subsection{Analysis of hydrogen permeability with the diffusion equation based on hydrogen chemical potential}

\subsubsection{Consistent description of hydrogen permeability}

It is known that the hydrogen diffusion is not always driven by the gradient of hydrogen concentration, $d c / d x$. Strictly speaking, the driving force for hydrogen diffusion is the gradient of hydrogen chemical potential, $d \mu / d x$. Recently, we have proposed a new description of hydrogen permeation through metal membrane based on hydrogen chemical poten$\operatorname{tial}^{21)}$. The diffusion equation based on hydrogen chemical potential is expressed as follows ${ }^{22)}$,

$$
J=-c B \frac{d \mu}{d x}
$$

where $B$ is the mobility of hydrogen atom and $c$ is the hydrogen concentration. Assuming the following three conditions, eq. (4) can be modified into eq. (5). (i) The hydrogen permeation reaction reaches to the steady state condition, (ii) the equilibrium condition is established between gaseous hydrogen and dissolved hydrogen atom on the top surface of the metal membrane, and (iii) the mobility, $B$, is independent of the hydrogen concentration.

$$
J=\frac{R T B}{2 L} \int_{c_{2}}^{c_{1}} c \frac{d \ln \left(P / P^{0}\right)}{d c} d c=\frac{R T B}{2 L} f_{\mathrm{PCT}},
$$

where $R$ is the gas constant, $T$ is absolute temperature, $c_{1}$ and $c_{2}$ are the hydrogen concentrations at the feed and permeation sides of the membrane, respectively. $P$ is applied hydrogen pressure and $P^{0}$ is the standard hydrogen pressure (i.e. $101325 \mathrm{~Pa}$ ). The integral term in eq. (5) is redefined as the PCT factor, $f_{\mathrm{PCT}}$, which can be determined by analyzing the corresponding PCT curve of the material of the membrane. The validity of eq. (5) has been confirmed by a series of hy-

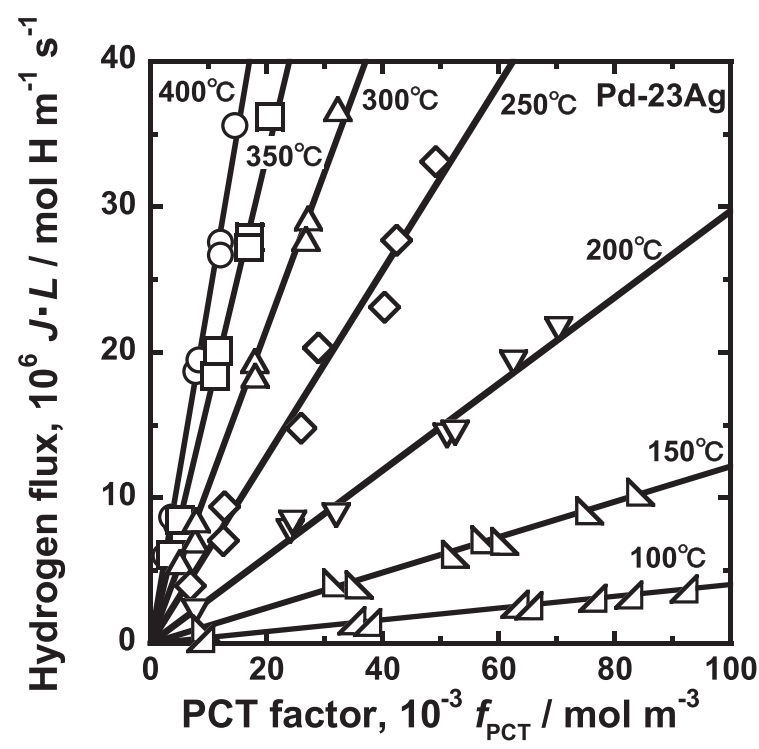

Fig. 6 Correlation between the normalized hydrogen flux, $J \cdot L$ and the PCT factor, $f_{\mathrm{PCT}}$, for Pd-23mol\%Ag alloy membrane.

drogen permeation tests with pure niobium, $\mathrm{Nb}$-based alloy and Pd-based alloy membranes ${ }^{21,23,24)}$.

Figure 6 shows the correlation between the normalized hydrogen flux, $J \cdot L$, and the PCT factor, $f_{\mathrm{PCT}}$, for $\mathrm{Pd}-23 \mathrm{~mol} \% \mathrm{Ag}$ at $100^{\circ} \mathrm{C} \sim 400^{\circ} \mathrm{C}$. The $f_{\mathrm{PCT}}$ value at each temperature and pressure condition is estimated from the PCT curves for $\mathrm{Pd}-$ $23 \mathrm{~mol} \% \mathrm{Ag}$ shown in Fig. 4. As shown in Fig. 6, there is linear relationship between $J \cdot L$ and the PCT factor, $f_{\mathrm{PCT}}$, even at low temperature. Each line shown in Fig. 6 crosses at the origin, indicating that the hydrogen permeation reaction takes place following eq. (5). The slope of the line shown in Fig. 6 is $R T B / 2$. Thus, the mobility, $B$, is almost constant at each temperature and independent of hydrogen concentration, in good agreement with the assumption (iii). Thus, the hydrogen permeation property for $\mathrm{Pd}-23 \mathrm{~mol} \% \mathrm{Ag}$ can be understood correctly over a wide temperature range based on eq. (5). Here, eq. (5) includes the mobility, $B$, which represents the hydrogen diffusivity, and the PCT factor, $f_{\mathrm{PCT}}$, which represents the hydriding property. Therefore, the temperature dependence of these two factors is analyzed separately below.

\subsubsection{Analysis of mobility for hydrogen diffusion during hydrogen permeation}

It is noted here that the hydrogen pressure at each feed and permeation side is constant in Fig. 1. Therefore, the temperature dependence of $\Phi$ shown in Fig. 1 is same as that of $J$ indicated by eq. (1). Therefore, the temperature dependence indicated in Fig. 1 can be discussed based on eq. (5).

As mentioned before, the slope of the line shown in Fig. 6 is $R T B / 2$. Thus, the mobility for hydrogen diffusion during hydrogen permeation can be evaluated from the slope of the line shown in Fig. 6. Figure 7 shows the Arrhenius plot of the mobility, $B$, for hydrogen diffusion during hydrogen permeation for $\mathrm{Pd}-23 \mathrm{~mol} \% \mathrm{Ag}$. As shown in Fig. 7, there is almost linear, but slightly curved relationship. The curvature is negative, and the activation energy and / or the frequency factor for hydrogen diffusion seem to increase with decreasing temperature. However, it is noted here that the mobility, $B$, decreases monotonically with decreasing temperature and 


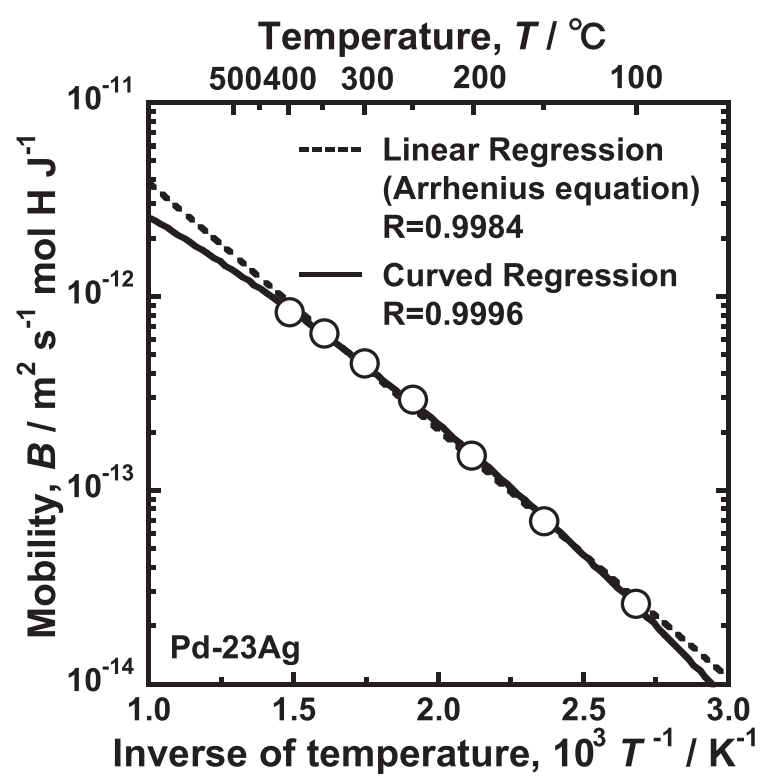

Fig. 7 Arrhenius plot of mobility for hydrogen diffusion for $\mathrm{Pd}-23 \mathrm{~mol} \% \mathrm{Ag}$ alloy.

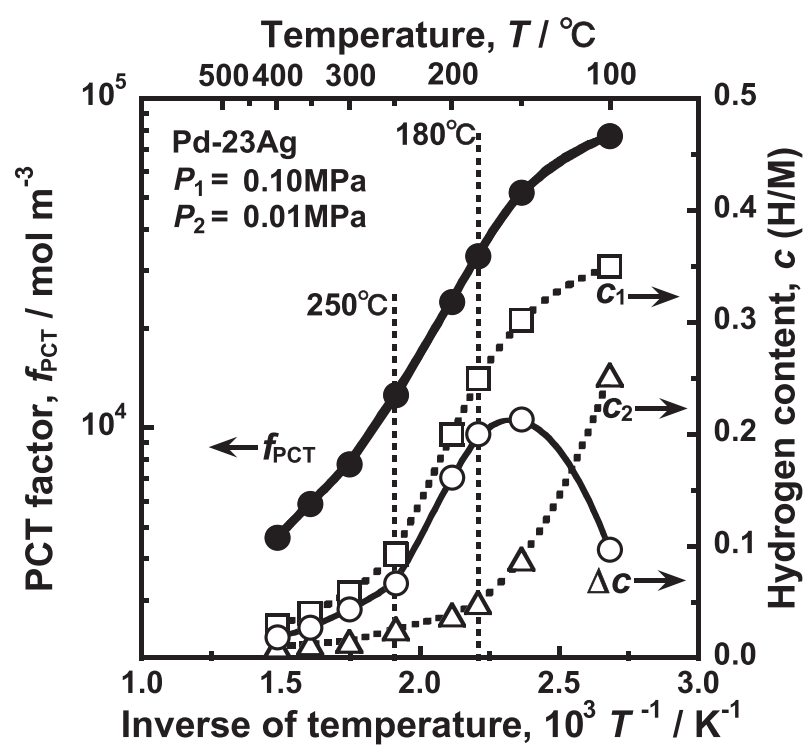

Fig. 8 Temperature dependence of the PCT factor, $f_{\mathrm{PCT}}$, the hydrogen concentration at each feed and permeation side of the membrane, $c_{1}$ and $c_{2}$, and their difference, $\Delta c$, for $\mathrm{Pd}-23 \mathrm{~mol} \% \mathrm{Ag}$ under the pressure condition of the feed and permeation sides are fixed to be $0.10 \mathrm{MPa}$ and $0.01 \mathrm{MPa}$, respectively.

anomalous temperature dependence is not observed. Therefore, it is thought that the reason for the peak observed in Fig. 1 is not the temperature dependence of the hydrogen diffusivity, but that of the hydriding property.

\subsubsection{The temperature dependence on PCT factor}

Figure 8 shows the temperature dependence of the PCT factor, $f_{\mathrm{PCT}}$. The hydrogen concentration at each feed and permeation side of the membrane, $c_{1}$ and $c_{2}$, and their difference, $\Delta c$ are also plotted in the figure. These parameters are estimated at $0.10 \mathrm{MPa}$ for feed side and $0.01 \mathrm{MPa}$ for permeation side, respectively. $\Delta c$ corresponds to the integral interval in eq. (5). As shown in Fig. 8, $c_{1}$ and $c_{2}$ increase monotonously with decreasing temperature under the constant pressure con-

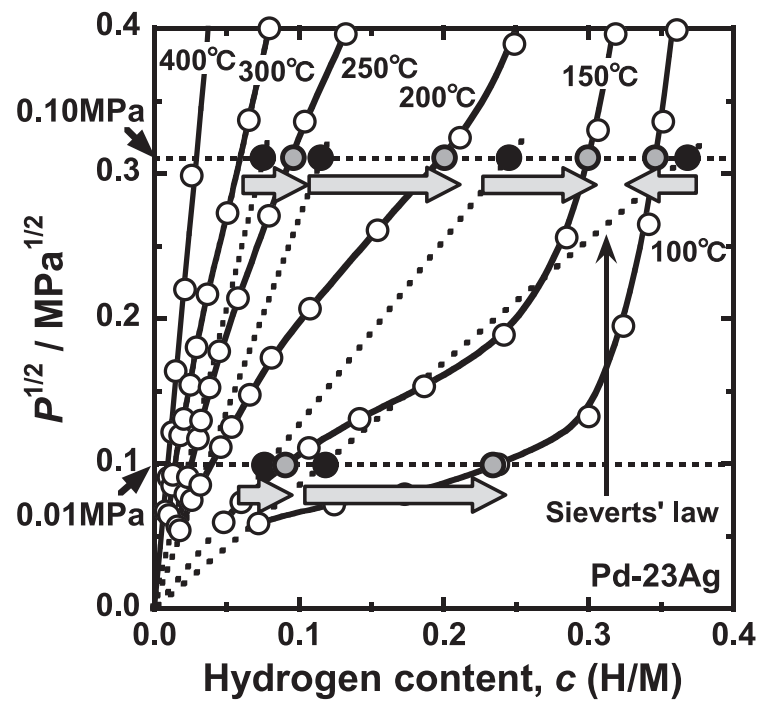

Fig. 9 PCT curves for Pd-23mol\% Ag alloy at low pressure range.

dition because the hydrogen dissolution reaction into $\mathrm{Pd}-$ $23 \mathrm{~mol} \% \mathrm{Ag}$ alloy is exothermic. Then, below about $250^{\circ} \mathrm{C}$, only $c_{1}$ increases significantly, and $\Delta c$ also increases significantly. As the result, the integral interval, $c_{2} \sim c_{1}$, and the hydrogen concentration, $c$, in eq. (5) increases, and $f_{\mathrm{PCT}}$ also increases significantly. In addition, below about $150^{\circ} \mathrm{C}, c_{1}$ turns to increase moderately and $c_{2}$ increases significantly, and $\Delta c$ turns to decrease. Although $\Delta c$ decreases, $f_{\mathrm{PCT}}$ continues to increase because the hydrogen concentration keeps increasing, but the gradient declines. Thus, $\Delta c$ has the peak around $150^{\circ} \mathrm{C}$ near the peak temperature shown in Fig. 1 .

As shown in Fig. 7, the mobility, $B$, decreases almost linearly with decreasing temperature. In contrast, the PCT factor, $f_{\mathrm{PCT}}$, increases monotonically with decreasing temperature. As shown in eq. (5), the temperature dependence of $J$ is the product of $B$ and $f_{\mathrm{PCT}}$, and be determined by the balance between two factors. As shown in Fig. 7 and Fig. 8, at higher temperature above $300^{\circ} \mathrm{C}$, the positive slope of $f_{\mathrm{PCT}}$ is more moderate than that of the negative slope of $B$, and $J$ decreases with decreasing temperature following eq. (5). On the other hand, at low temperature below $250^{\circ} \mathrm{C}, f_{\mathrm{PCT}}$ increases significantly, and the hydrogen flux, $J$, turns to increase. However, at lower temperature below $150^{\circ} \mathrm{C}$, the slope of $f_{\mathrm{PCT}}$ becomes moderate, and the hydrogen flux, $J$, turns to decrease again. In this way, the temperature dependence of the hydrogen permeability shows a peak as shown in Fig. 1. The slope of $f_{\mathrm{PCT}}$ at lower temperature below $180^{\circ} \mathrm{C}$ is more gradual than that at higher temperature above $300^{\circ} \mathrm{C}$ as shown in Fig. 8. Therefore, as shown in Fig. 1, the slope of the line below $180^{\circ} \mathrm{C}$ is steeper than that above $300^{\circ} \mathrm{C}$. Thus, it is found that the peak observed in Fig. 1 can be understood by the temperature dependence of the PCT factor, $f_{\mathrm{PCT}}$.

Figure 9 shows the PCT curves at the low pressure range up to $0.16 \mathrm{MPa}$ reproduced from Fig. 4. In this figure, square root of hydrogen pressure is plotted as a function of hydrogen concentration. Thus, there is a linear relationship if the Sieverts' law is applicable. As shown in Fig. 9, the hydriding property is expressed in the Sievert's law at high temperature above $300^{\circ} \mathrm{C}$. However, around $250^{\circ} \mathrm{C}$, the hydrogen concen- 


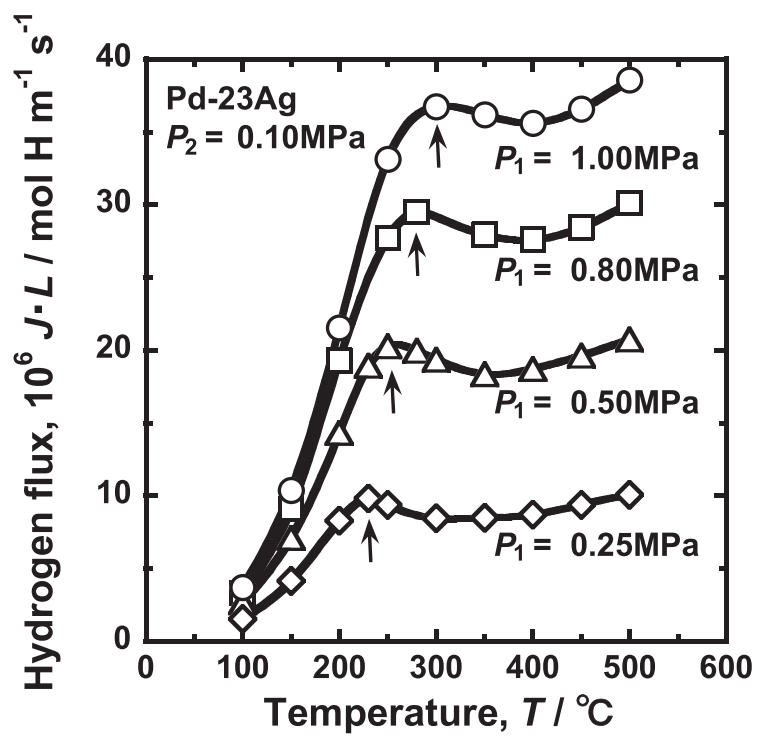

Fig. 10 The temperature dependence of the normalized hydrogen flux, $J \cdot L$ for $\mathrm{Pd}-23 \mathrm{~mol} \% \mathrm{Ag}$ alloy membrane under the pressure condition of the feed side, $P_{1}$, is $1.00 \mathrm{MPa}, 0.80 \mathrm{MPa}, 0.50 \mathrm{MPa}$ and $0.25 \mathrm{MPa}$, and the permeation side pressure, $P_{2}$, is fixed to be $0.10 \mathrm{MPa}$.

tration at the feed side (i.e., high pressure side) becomes larger than the value estimated by the Sievert's law. It is known that this phenomenon occurs due to the lattice expansion by the dissolved hydrogen atoms ${ }^{22}$. This deviation from the ideal hydriding property is the reason for the significant increase in $c_{1}$ shown in Fig. 8. On the other hand, around $150^{\circ} \mathrm{C}$, the gradient of the PCT curve at the feed side pressure region becomes steeper. It is known that this is because the repulsive interaction arises between dissolved hydrogen atoms with increasing hydrogen concentration ${ }^{22)}$. In addition, the hydrogen concentration at the permeation side (i.e., low pressure side) becomes larger than the value estimated by the Sieverts' law. These are the reasons for the decrement of $\Delta c$, which will lead to decrease the hydrogen permeability below $180^{\circ} \mathrm{C}$ as shown in Figs. 8 and 1. In other words, it is shown that the deviation of the actual hydriding property from the Sieverts' law caused by the hydrogen-induced interaction is dominant for the appearance of the peak observed in Fig. 1.

It is important to note here that the hydrogen permeability reflects the shape of the corresponding PCT curve, and eq. (5) is useful for the understanding of the unique temperature dependence of $\mathrm{Pd}-\mathrm{Ag}$ alloy membrane shown in Fig. 1.

\subsection{Effect of pressure condition on the peak behavior of hydrogen permeability}

As mentioned in the previous section, the peak shown in Fig. 1 can be understood by the corresponding PCT curves of the material. Therefore, it is expected that the peak behavior will be affected by the pressure conditions. In this section, the influence of the pressure condition on the peak behavior is discussed.

Figure 10 shows the correlation between the normalized hydrogen flux, $J \cdot L$ and the temperature, $T$, for $\mathrm{Pd}-$ $23 \mathrm{~mol} \% \mathrm{Ag}$ when the feed side pressures are $1.00 \mathrm{MPa}$, $0.80 \mathrm{MPa}, 0.50 \mathrm{MPa}$ and $0.25 \mathrm{MPa}$, and the permeation side pressure is $0.10 \mathrm{MPa}$. As mentioned above, the hydriding property is not expressed in the Sieverts' law at low tempera-

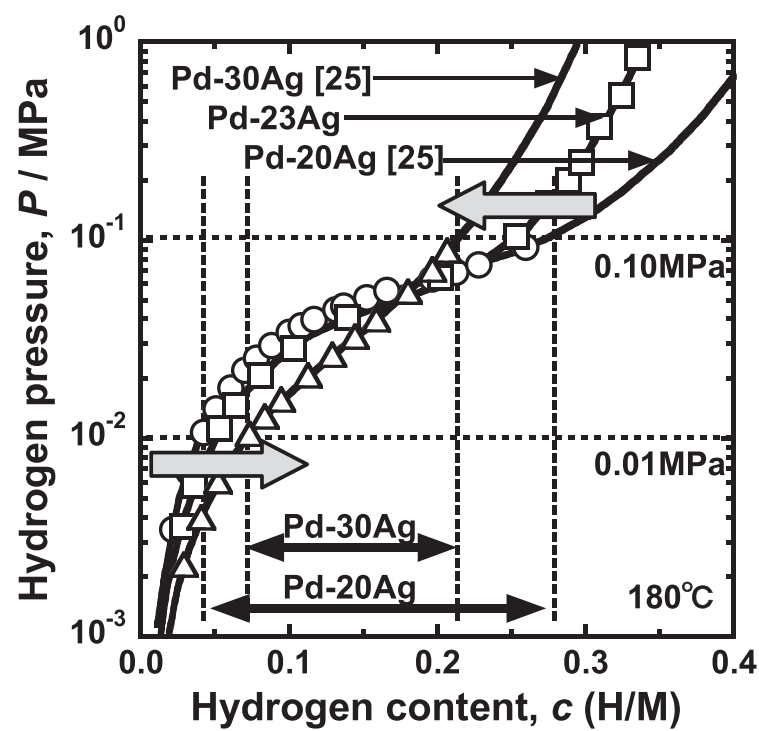

Fig. 11 PCT curves for $\mathrm{Pd}-20 \mathrm{~mol} \% \mathrm{Ag}^{25)}, \mathrm{Pd}-23 \mathrm{~mol} \% \mathrm{Ag}, \mathrm{Pd}-$ $30 \mathrm{~mol} \% \mathrm{Ag}^{25)}$ at $180^{\circ} \mathrm{C}$.

ture, and the hydrogen permeability should not be evaluated by the hydrogen permeation coefficient, $\Phi$, based on the Sieverts' law. Therefore, $J \cdot L$ is plotted as a function of $T$ in Fig. 10. As shown in Fig. 10, the peak of $J \cdot L$ is observed over wide pressure conditions. It is found that the peak temperature increases with increasing the feed side pressure. This is because the hydriding property at higher hydrogen pressure region starts to deviate from the Sievert's law at higher temperature. Thus, the peak temperature depends on the pressure condition, but the dependence can be understood by the corresponding PCT curves. It is confirmed again that the hydrogen permeability reflects the shape of the corresponding PCT curves, and they are essential for the understanding of hydrogen permeation property of the alloy membranes.

\subsection{Influence of silver concentration on the peak behav- ior of hydrogen permeability}

As mentioned above, the hydriding property of the material is important for the understanding of the peak behavior of hydrogen permeability. In other words, it is thought that the change in the shape of the PCT curves affects the peak behavior. In this section, the dependence of the silver concentration on the peak behavior of the hydrogen permeability in $\mathrm{Pd}-\mathrm{Ag}$ binary alloys is investigated.

Figure 11 shows the PCT curves for $\mathrm{Pd}-20 \mathrm{~mol} \% \mathrm{Ag}^{25)}$, $\mathrm{Pd}-23 \mathrm{~mol} \% \mathrm{Ag}$ and $\mathrm{Pd}-30 \mathrm{~mol} \% \mathrm{Ag}^{25)}$ at $180^{\circ} \mathrm{C}$. For $\mathrm{Pd}-\mathrm{Ag}$ binary alloys, it is known that the hydrogen concentration at low pressure range increases with increasing silver concentration as shown in Fig. 11 because the addition of silver into palladium expanses the crystal lattice of the alloy. In contrast, the hydrogen concentration at high pressure range inversely decreases. The reason is generally understood based on the band theory. The $4 \mathrm{~d}$ band of palladium has been already filled by the valence electrons of silver, and the electrons from dissolved hydrogen atoms need to occupy the $5 \mathrm{~s}$ band, which has low density of states, resulting in steep rise of the Fermi level from lower hydrogen concentration range ${ }^{26)}$. In view of these alloying effects of silver, it is expected that $\Delta c$ becomes 


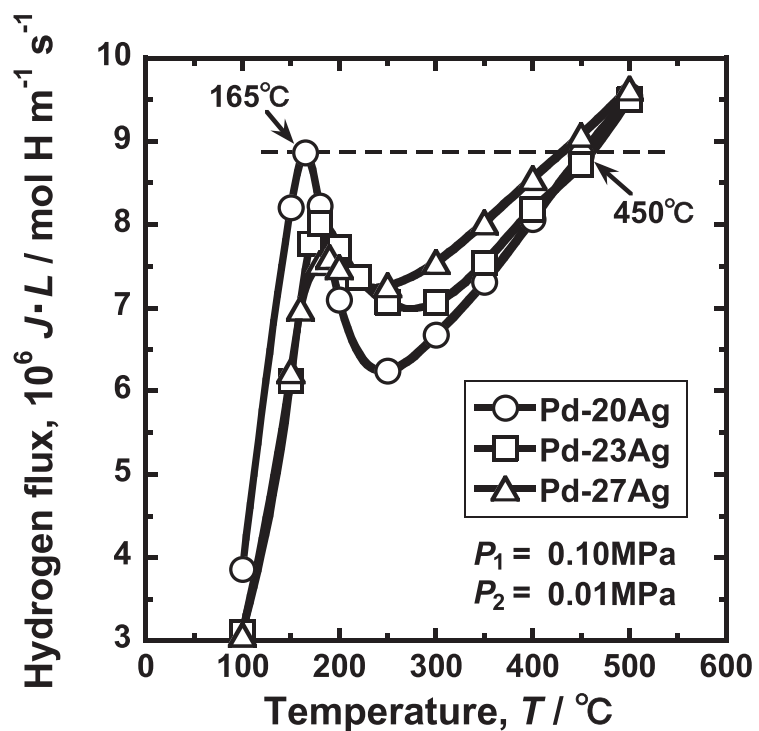

Fig. 12 The temperature dependence of the normalized hydrogen flux, $J \cdot L$ for $\mathrm{Pd}-20 \mathrm{~mol} \% \mathrm{Ag}, \mathrm{Pd}-23 \mathrm{~mol} \% \mathrm{Ag}$ and, $\mathrm{Pd}-27 \mathrm{~mol} \% \mathrm{Ag}$ alloy membranes. The pressure conditions of the feed and permeation sides are fixed to be $0.10 \mathrm{MPa}$ and $0.01 \mathrm{MPa}$, respectively.

large with decreasing silver concentration at low temperature as shown in Fig. 11, and the peak becomes more remarkable.

Figure 12 shows the correlation between the normalized hydrogen flux, $J \cdot L$ and the temperature, $T$, for $\mathrm{Pd}-$ $20 \mathrm{~mol} \% \mathrm{Ag}, \mathrm{Pd}-23 \mathrm{~mol} \% \mathrm{Ag}$ and $\mathrm{Pd}-27 \mathrm{~mol} \% \mathrm{Ag}$. Hydrogen pressures at the feed and permeation sides are fixed to be $0.10 \mathrm{MPa}$ and $0.01 \mathrm{MPa}$, respectively. As shown in Fig. 12, the peak of $J \cdot L$ for Pd-20mol\%Ag is the most significant in this study. It is also found that the peak temperature reduces with decreasing silver concentration. The peak temperature for $\mathrm{Pd}-20 \mathrm{~mol} \% \mathrm{Ag}$ is about $165^{\circ} \mathrm{C}$ and the value of $J \cdot L$ at $165^{\circ} \mathrm{C}$ is almost the same as that at $450^{\circ} \mathrm{C}$, about $285^{\circ} \mathrm{C}$ higher temperature. By lowering silver concentration, the same hydrogen permeability at higher temperature is obtained at lower temperature. At $450^{\circ} \mathrm{C}$, the heat resistance of the materials of the surrounding components for hydrogen production system is highly required. On the other hand, $165^{\circ} \mathrm{C}$ is so moderate temperature that the demand for the heat resistance can be greatly lowered. Thus, by controlling the silver concentration, it is possible to expand the possibility of the application of the peak behavior.

It is also noted that the critical temperature for the $\alpha-\alpha$ ' transition, $T_{\mathrm{c}}$, for $\mathrm{Pd}-20 \mathrm{~mol} \% \mathrm{Ag}$ is about $55^{\circ} \mathrm{C}$ as shown in Fig. 4. Therefore, the $\alpha-\alpha^{\prime}$ transition does not occur at $165^{\circ} \mathrm{C}$ for $\mathrm{Pd}-20 \mathrm{~mol} \% \mathrm{Ag}$ alloy. However, by lowering further silver concentration to obtain more remarkable peak, the $T_{\mathrm{c}}$ comes close to the peak temperature. Therefore, it is important for applying the peak behavior to determine silver concentration in view of the balance between the $T_{\mathrm{c}}$ and the peak temperature. As mentioned before, it is known that the optimal silver concentration for $\mathrm{Pd}-\mathrm{Ag}$ alloy membrane is about $23 \mathrm{~mol} \%$ at high temperature ${ }^{6,7)}$. However, at low temperature, the hydrogen permeability of the alloy with lower silver concentration is higher at the peak temperature. Thus, the optimal composition of $\mathrm{Pd}-\mathrm{Ag}$ alloys differs depending on the operating temperature and the pressure condition. The composition can be determined in view of the PCT curve and eq. (5).
This study suggests new possibilities of alloy design for $\mathrm{Pd}-\mathrm{Ag}$ alloy membranes. In addition, the other alloying elements should be investigated. It is possible that more remarkable peak is observed by the addition of third element into $\mathrm{Pd}-\mathrm{Ag}$.

\section{Summary}

The hydrogen permeability of $\mathrm{Pd}-\mathrm{Ag}$ alloy membranes has been investigated over a wide temperature range. The hydrogen permeation coefficient, $\Phi$, for $\mathrm{Pd}-23 \mathrm{~mol} \% \mathrm{Ag}$ alloy does not decrease monotonically with decreasing temperature, but it starts to increase from $250^{\circ} \mathrm{C}$ and a peak is observed around $180^{\circ} \mathrm{C}$. The value of $\Phi$ at the peak temperature is almost the same as that of $400^{\circ} \mathrm{C}$, indicating that the same hydrogen permeability at high temperature is obtained at significantly low temperature.

In the previous study, the $\alpha-\alpha^{\prime}$ phase transition has been noted as the reason for the peak appearance. However, for the composition of $\mathrm{Pd}-\mathrm{Ag}$ alloy investigated in this study, the $\alpha-\alpha$ ' transition does not occur at the temperature condition. Thus, the peak behavior will be applicable without declining the durability of the membrane due to the $\alpha-\alpha^{\prime}$ phase transition. In addition, it is also confirmed that the diffusion-limiting hydrogen permeation reaction takes place from room temperature up to $500^{\circ} \mathrm{C}$.

To understand the peak behavior, the hydrogen diffusivity and hydriding property have been analyzed separately in view of the new description of hydrogen permeation based on hydrogen chemical potential. For the hydrogen diffusivity, notable behavior is not observed even around the peak temperature. On the other hand, the temperature dependence of the PCT factor, $f_{\mathrm{PCT}}$, which represents the hydriding property, changes around the peak temperature. It is found that the deviation of the actual hydriding property from the Sieverts' law results in the change of the PCT factor, $f_{\mathrm{PCT}}$, and is dominant for the peak of the hydrogen permeability.

The dependence of the pressure condition and the silver concentration on the peak behavior has also been investigated. Under fixed hydrogen pressure at permeation side, the peak temperature increases with increasing the hydrogen pressure at feed side. In addition, with decreasing silver concentration, the peak appears at lower temperature and more remarkable. These results indicate that it is important to determine the optimal composition of $\mathrm{Pd}-\mathrm{Ag}$ alloy membranes depending on the operating condition and the corresponding PCT curves. Thus, this study suggests new possibilities of alloy design and application of $\mathrm{Pd}-\mathrm{Ag}$ alloy membranes.

\section{Acknowledgement}

This research was supported in part by CREST project from Japan Science and Technology Agency (JST) and Grantin-Aid for Scientific Research from Japan Society for the Promotion of Science (JSPS).

\section{REFERENCES}

1) E. Kikuchi: Catal. Today 56 (2000) 97-101.

2) G. Meunier and J.P. Manaud: Int. J. Hydrogen Energ. 17 (1992) 599- 
602.

3) S. Tosti: Int. J. Hydrogen Energ. 28 (2003) 1445-1454.

4) S.C. Chen, C.C.Y. Hung, G.C. Tua and M.H. Rei: Int. J. Hydrogen Energ. 33 (2008) 1880-1889.

5) S.N. Paglieri and J.D. Way: Separation \& Purification Reviews 31 (2002) $1-8$.

6) A.G. Knapton: Platin. Met. Rev. 21 (1977) 44.

7) A.S. Darling: Chemie-Ing. -Techn. 37 (1965) 18.

8) F.D. Manchester, A. San-Martin and J.M. Pitre: J. Phase Equi. 15 (1994) 62-83

9) H. Brodowsky and E. Poeschel: Z. Phys. Chem. NF 44 (1965) 143159.

10) H. Buck and G. Alefeld: Phys. Status Solidi B 49 (1972) 317-327.

11) H. Brodowsky and E. Wicke: Engelhard Ind. Techn. Bull. 7 (1966) $41-50$.

12) M. Nuovo, F.M. Mazzolai and F.A. Lewis: J. Less Common Met. 49 (1976) 37-48.

13) F.M. Mazzolai and F.A. Lewis: J. Phys. F Met. Phys. 3 (1973) L258L262.

14) F.M. Mazzolai, F.A. Lewis: Int. Fric. Utlr. Atten. Solid, (1977) 467471.

15) J.S. Carlow and R.E. Meads: J. Phys. F Met. Phys. 2 (1972) 982-984.
16) Y. Sakamoto, K. Yuwasa and K. Hirayma: J. Less Common Met. 88 (1982) 115-124.

17) T. Nambu, N. Shimizu, H. Ezaki, H. Yukawa and M. Morinaga: J. Japan Inst. Metals 69 (2005) 841.

18) A.L. Mejdell, H. Klette, A. Ramachandran, A. Borg and R. Bredesen: J. Membr. Sci. 307 (2008) 96-104.

19) E. Serra, M. Kemali, A. Perujo and D.K. Ross: Metall. Mater. Trans., A Phys. Metall. Mater. Sci. 29A (1998) 1023.

20) J. Okazaki, D.A. Pacheco Tanaka, Margot A. LIosa Tanco, Y. Wakui, F. Mizukami and T.M. Suzuki: J. Member, Sci. 282 (2006) 370-374.

21) A. Suzuki, H. Yukawa, T. Nambu, Y. Matsumoto and Y. Murata: Int. J. Hydrogen Energ. 39 (2014) 7919-7924.

22) Y. Fukai: The Metal-Hydrogen System. Springer, (1993) 13-16.

23) A. Suzuki, H. Yukawa, T. Nambu, Y. Matsumoto and Y. Murata: J. Alloy. Compd. 645 (2015) S107-S111.

24) A. Suzuki, H. Yukawa, T. Nambu, Y. Matsumoto and Y. Murata: J. Membr. Sci. 503 (2016) 110-115.

25) R. Lässer, P. Meuffels and R. Feenstra: KFA-Jülich Report No.2183. (1988).

26) G. Alefeld and J.Volk1: Hydrogen in Metals II, Springer, Berlin (1978) 118-134. 